\title{
Kant on Non-Veridical Experience
}

\begin{abstract}
In this paper I offer an interpretation of Kant's theory of perceptual error based on his remarks in the Anthropology. Both hallucination and illusion, I argue, are for Kant species of experience and therefore require the standard co-operation of sensibility and understanding. I develop my account in a conceptualist framework according to which the two canonical classes of non-veridical experience involve error in the basic sense that how they represent the world as being is not how the world is. In hallucination this is due to the misapplication of categories and in illusion to the misapplication of empirical concepts. Yet there is also room in this framework for a distinction in terms of cognitive functionality between the level of experience, which is merely judgementally structured, and that of judgement proper, which involves the free action of a conscious agent. This distinction enables Kant to allow for the otherwise problematic phenomenon of self-aware non-veridicality.
\end{abstract}

\section{Introduction}

Non-veridical experience has been a central topic in epistemology and philosophy of mind since at least the time of Descartes. Even disregarding worries about radical sceptical scenarios in which experience is globally delusive, the residual but trenchant issue of how to deal with local delusion remains the dividing question in analytic philosophy of perception. ${ }^{1}$ Yet little has been written that explicitly aims to expound Kant's views on the matter. ${ }^{2}$ My aim in this article is to begin to remedy this fact. Doing so will not only shed new light on the on-going debate concerning the fundamental nature of Kant's theory of human experience; it will also expose certain Kantian tools that have so far gone unexploited in contemporary discussion.

I will not be directly concerned with Kant's relation to any form of scepticism, but rather with his account of the particular mechanisms of non-veridical experience. Kant's

\footnotetext{
${ }^{1}$ See Crane (2006).

${ }^{2}$ One notable exception is Beck (1978), whose account differs markedly from mine. A recent two-part article by Frierson (2009) discusses Kant's account of mental disorder at length and also focuses on the Anthropology, but his concern is primarily with psychiatric and practical issues. My thanks to Dan Robinson for bringing this paper to my attention.
} 
most extended remarks concerning these mechanisms occur in his Anthropology From a Pragmatic Point of View. Like the topic itself, this is a text that has been almost entirely neglected in the literature on the theoretical philosophy, ${ }^{3}$ and it is another key aim of this article is to begin to remedy this fact as well.

First I outline how sensibility $(\S 1)$ and the understanding $(\S 2)$ function in cases of hallucinatory experience. Then, partly by way of shading in this outline, I explain how Kant's model also has a place for illusion (§3), before further addressing the general issue of how it can cope with cases in which the subject is aware that her experience is in some way non-veridical (\$4). Finally I offer some very brief, largely promissory remarks about the potential consequences of my account (\$5).

\section{1.}

Hallucination is the experience as of an object when no object is present. A canonical example is Macbeth's seeing a dagger before him, the handle toward his hand. There are plenty of complications if one goes into the details of the notion but this much will suffice here.

Hallucination, as a species of experience, must involve sensibility. This lower mental faculty is commonly characterized in terms of passive receptivity. What it is for us to possess a passive faculty for receptivity is for us to be able to receive information about the surrounding environment merely through being causally affected by it. And what it is for us to have representations that belong to this faculty is for such information to get encoded in mental states that have their sufficient causes in - are nothing but a causal effect of - sensory stimulation - light being reflected to strike the retina and dissipate molecules of fatty acid, for example. ${ }^{4}$ Kant calls these representations sensations or intuitions, which for present purposes I will take to be roughly equivalent (though I am

\footnotetext{
${ }^{3}$ One notable exception is Brandt (1999).

${ }^{4}$ The notion of information-encoding might sound rather anachronistic but it is simply supposed latch on to the idea that the different representations at this very low level of mental function have different features in virtue of the different circumstances in which they are brought about, and that it is these features that are exploited in various ways by the higher faculties in whatever subsequent cognitive role such representations are to play. Sellars (1968) talks about this in terms of counterpart properties.
} 
far more neutral on this controversial matter than such a stipulation might suggest, which fact I return to in the last section).

However, what is crucial for hallucination is that there is a sense in which sensibility is not entirely passive. Kant's model of the human mind is essentially that of a dataprocessor, with input, function, and output. ${ }^{5}$ Sensibility's role is to provide the input, without which 'there would be no material that could be processed' (144). ${ }^{6}$ In itself this role dictates nothing about the source of that data. The bare fact that a data-processor needs informational input creates logical space for a certain restricted degree of underdetermination in this regard. I say 'restricted' because I do not mean to introduce sceptical worries about malign supernatural implantation or brains in vats. Let us suppose for the sake of argument that we fix the distal origin of our data as genuine causal affection by external physical objects. It nevertheless remains a possibility that once such data has been originally received - once genuine causal affection has occurred - it could somehow be regurgitated after the fact and then presented for processing in the normal way. Such would remain the work of sensibility, understood as data-provider, and yet would require more than sheer passivity. This active element to sensibility, I propose, is at least one of the roles Kant intends for the imagination (though it certainly plays others):

Sensibility in the cognitive faculty (the faculty of representations in intuition) contains two parts: sense and the power of imagination. - The first is the faculty of intuition in the presence of the object, the second even without the presence of it. (153)

The power of imagination (facultas imaginandi), as a faculty of intuition even without the presence of the object, is either productive, that is, a faculty of the original presentation of the object (exhibitio originaria), which thus precedes

\footnotetext{
${ }^{5}$ For discussion of this general interpretive approach see Hanna (2001, 14-66) and Longuenesse (1998, 35-58).

6 All in-text page references are to volume VII of the Akademieausgabe, which contains Kant's Anthropologie in pragmatischer Hinsicht. References to other of Kant's works are restricted to footnotes and, with the exception of the Kritik der reinen Vernunft, are given by volume and page number of the Akademieausgabe along with a short English title. References to the Kritik take the standard A/B format. I follow the English translations of The Cambridge Edition of the Works of Immanuel Kant but have made modifications where deemed appropriate. The details of the particular volumes I have used from the Cambridge collection are contained in the bibliography.
} 
experience; or reproductive, a faculty of the derivative presentation of the object (exhibitio derivativa), which brings back to the mind an empirical intuition had previously. (167) ${ }^{7}$

And Kant even goes on to point out the ultimately parasitic nature of the imagination in this naturalistic guise:

The power of imagination (in other words) is either inventive (productive), or merely recollective (reproductive). But the productive power of imagination is nevertheless not exactly creative, for it is not capable of producing a sense representation that was never given to our faculty of sense; one can always furnish evidence of the material of its representations. To one who has never seen red among the seven colours, we can never make this sensation comprehensible... the sensations produced by the five senses in their composition cannot be made by means of the power of imagination, but must be drawn originally from the faculty of sense. $(167-8)^{8}$

The imagination normally plays such a role in cognitive processes that are entirely epistemically legitimate, like memory $(182-5),{ }^{9}$ but there is room here for an altogether more pernicious function - in hallucination.

Consider the following picture. In veridical experiences there is an object that is causally affecting us at the time of the experience and in virtue of which act of sensing we acquire a manifold of intuitions. In hallucinatory experience, however, there is no such object, no such causal affection, and no such act of sensing. Instead there is the imaginative recall of a previously acquired manifold (perhaps even one that has been somehow carved up and combined with other parts of previously acquired manifolds). It is this (perhaps gerrymandered) manifold that is then presented for intellectual

\footnotetext{
${ }^{7}$ Cf. Metaphysics Mrongrovius (29:881), Metaphysics Volckmann (28:449), Metaphysics L 2 (28:585), Metaphysics Dohna (28:672).

${ }^{8}$ Cf. A770-1/B798-9, and the Vienna Logic (24:904).

${ }^{9}$ It would be entirely appropriate to be reminded of Hume (1978) in observing this connection to memory, as there is much in the following account that parallels the role he attributes to the imagination. I cannot go into this topic here but I should note that it differs significantly from the aspect of the relation between Kant and Hume's theories of imagination discussed, for example, in Strawson (1971).
} 
processing. What results is an experience as of whatever object originally caused the relevant intuitions, but without the actual and current presence of that object. ${ }^{10}$

Furthermore it seems entirely possible that things might go awry in this way without us noticing or even being able to notice. On the data-processor model there might be nothing intrinsic to the data we process that tells us whether it is the result of current affection or rather of some more surreptitious procedure. Again we need not go as far as entertaining radical sceptical hypotheses. Indeed, we might even concede that there is always something intrinsic to the data that could tell us this much, at least when we take a large enough collection of it. It would still seem entirely possible that this feature is not always accessible to us, and this is sufficient to motivate the present worry. Kant himself gestures towards this issue of the apparent possibility of subjective indistinguishability:

the power of the imagination, which puts material under the understanding in order to provide content for its concepts (for cognition), seems to provide a reality to its (invented) intuitions because of the analogy between them and real perceptions. (169) $)^{11}$

At the level at which representations are processed, there might, at least under certain circumstances, be no way to tell the proximal origin of those representations. Or to put it another way, the higher faculties cannot as it were reach down into sensibility in order to check which part of it, sense or imagination, is currently activated.

So far I have talked as though the imagination provides information for processing directly, bypassing passivity altogether. In fact we need to complicate this picture slightly because of certain things Kant says in this context about a division in the passive part of sensibility:

\footnotetext{
${ }^{10}$ Something very similar is implied at B278. Allais $(2010,59)$ points out that Kant talks about intuitive representation there, rather than intuition as such, but in light of the passages we have just seen I cannot agree that this is particularly significant. Rather we should look more carefully at the oft-cited claim in the Prolegomena (4:281-2) that 'An intuition is a representation of the sort which would depend immediately on the presence of an object' - note the subjunctive tone and the fact that Kant goes on in the (rarely cited) next sentence to talk about an object's presence 'either previously or now'.

${ }^{11} \mathrm{He}$ is more explicit in the Prolegomena (4:290): 'The difference between truth and dream, however, is not decided through the quality of the representations that are referred to objects, for they are the same in both'. Cf. also B279.
} 
The senses, however, are in turn divided into outer and inner sense (sensus internus). The first is where the human body is affected by physical things; the second, where it is affected by the mind. (153)

Suppose, then, that some passive part of sensibility is always involved in experience outer sense for veridical cases and inner sense for hallucination. After all, it seems right to say that hallucination involves actually undergoing sensuous modifications of the mind, rather than merely a punctiform episode of information recall. On this approach, the imagination fully replaces the object and is attributed similar causal powers. What distinguishes hallucination from veridical experience at this level of mental function is not the bypassing of the senses. It is simply that it is the imagination rather than the object that fulfils the role of causal instigator in cases of hallucination.

The addition of this intermediary step has the benefit of emphasising the important fact that the kind of imaginational activity currently under discussion is very different to intellectual activity. And it also suggests an intuitive alternative role for the otherwise difficult notion of inner sense. In other works Kant focuses on distinguishing inner sense from apperception and relating this distinction to the epistemic humility of transcendental idealism. ${ }^{12}$ But this matter 'does not really belong to anthropology' (142), so in his lectures on this subject he talks instead about

taking the appearances of inner sense for external appearances, that is, taking imaginings for sensations... it is mental illness: the tendency to accept the play of representations of inner sense as experiential cognition, although it is only fiction... and accordingly to trick oneself with the intuitions thus formed (dreaming when awake). (161)

Indeed I think it is generally fair to say that the account I have outlined brings us closer than most to the idea of imagination many of us would have prior to reading the Transcendental Deductions.

${ }^{12}$ See e.g. B153-6. 
We have seen what has to happen at the level of sensibility in order for hallucination to occur, but this is not the whole story. Hallucination is one kind of output of our cognitive system, and while we can suppose that there is a perfectly robust sense in which the input of sensibility constrains this output, it does not alone determine it. Different input can produce different output, but this can also depend on the nature of the functions that map one onto the other. ${ }^{13}$ In Kantian terms, as a species of experience, hallucination must also involve our higher mental faculty, the understanding.

More specifically, hallucination is a normative phenomenon at least insofar as it involves some kind of mistake. Yet sensibility, both in its passive and active part, functions entirely within the natural realm. Its representations are the immediate, unprocessed result of causal affection, and whether this occurs because of the object or because of the imagination, it is a natural event and in no sense assessable for correctness. Kant makes this absolutely crucial point in the following striking passage:

The senses do not deceive... not because they always judge correctly, but rather because they do not judge at all. Error is thus a burden only to the understanding. - Still, sensory appearances (species, apparentia) serve to exculpate, if not exactly to justify, understanding. $(146)^{14}$

It is the intellectual activity of the understanding - its act of information decoding - that first brings us into a normative realm at all. Kant's explicit ought-talk is largely restricted to the practical sphere, ${ }^{15}$ but his core machinery makes a certain structural connection to a certain kind of normativity clear: concepts can be correctly or incorrectly applied and judgements can be true or false. It is true that so far this is an extremely bare kind of normativity, in effect exhausted by truth-conditions. Indeed one might even question the wisdom of calling it normativity in the first place and later we

\footnotetext{
13 This is one way of stating the problem that McDowell (1996) and (1998) has addressed under the Sellarsian rubric of the Myth of the Given. More specifically that functions could produce output, if not without input, then in some sense regardless of it.

${ }^{14}$ Cf. A293/B350, Prolegomena (4:290-1), Metaphysics Mrongrovius (29:759, 833).

15 Though see A135-6/B174-5. My thanks to Ken Westphal for the pointer, who cites this passage in his (2004, 168).
} 
will have cause to turn briefly to a far richer and more uniquely Kantian notion. But it is significant enough for now that it is only once the understanding and its cognitive machinery becomes involved that representation, and thereby misrepresentation, is possible. The product of sensibility functioning alone does not represent the world as being a certain way at all, and so cannot be mistaken in even this very basic sense.

So exactly how does hallucination involve a mistake? Well in a nutshell the Kantian intellectual machinery works as follows: the concept of an object provides the rule in accordance with which the understanding processes the data it receives from sensibility; what it is for the understanding to carry out this process is for it to interpret that data as collectively indicative of the perceptual presence of an object; and the experience that is the result of this process has what I will call a judgemental counterpart - something like 'that there is an object here and now' - which is in effect the experience's content. Hallucination involves a mistake, then, in the sense that the concept of an object is misapplied, the data provided for intellectual processing in some sense should not be interpreted as indicative of the perceptual presence of an object, and the resultant judgemental counterpart is false.

Note that it is crucial for the application to hallucinatory cases that this judgemental counterpart to experience does not depend for its sense on the actual existence of its object. If there is in fact not an object here and now, then the claim that there is an object here and now is false, but at least it is meaningful. This application proscribes singularity of reference in virtue of demonstrative-type reference to a particular object; assuming, that is, that judgements that refer in such a way - judgements to the effect that that object is here and now - are not merely false but fail to have any determinate truth-value when they fail to refer because the object does not exist. But it is consistent with singularity of reference in virtue of spatiotemporal indexicality. So there is something analogous to demonstration about the judgemental counterpart to experience. It is just that it is not the object part that sustains the analogy. After all, the concept of an object is as general and descriptive as any other concept (as we will see in the next section). Rather what sustains the analogy are the spatiotemporal indexicals, and these are immune to reference failure - regardless of what objects happen to exist at the time 
and place of an experience, veridical or no, there is always a time and place to that experience. $^{16}$

Moreover, I take it that this reading of the judgemental counterpart to experience - as the claim that there is an object here and now - need not necessarily fly in the face of any facts about ordinary linguistic practice. Even if we do appear to use demonstratives in reporting on what we experience - 'this object exhibits such and such features' - it is not at all obvious that these reports really express any object-dependent content. And it would be thoroughly in-keeping with the current proposal that the demonstrative locution in such cases simply reflects a general default assumption that experience is veridical (as we will see in §4). The thought is that we tend to talk about our experiences as though they are object-dependent simply because we tend to believe that there is an object in the world that we are experiencing; that we tend to act as though it would not be a problem if our experience were object-dependent because we tend to presume we are experiencing an actual object. But that this practice and this assumption exist entails neither that the content of our experience is in fact object-dependent nor even that it is on reflection somehow more intuitive to say that it is. Nor, of course, was ordinary linguistic practice of particular concern to Kant.

This account of hallucination remains fairly skeletal. One way to flesh it out further would be to consider some salient variations on the theme. For example, how does Kant's model accommodate cases of partial hallucination? If only the dagger is unreal, and the courtyard in which Macbeth sees it situated is real, then it seems that his understanding cannot be entirely wrong in all its conceptualizing activity. And what about coincident hallucination? Suppose that what I hallucinate just so happens to coincide with the actual state of my environment, that the data my imagination provides just so happens to be exactly the same as the data my outer sense would have provided had I been experiencing veridically. Something has clearly gone wrong, and my experience will likely not be a suitable basis for knowledge, but concepts are instantiated and judgemental counterparts come out true. Finally, how can a subject hallucinate something she has never come across? Presumably it is possible to

\footnotetext{
${ }^{16}$ My thanks to Arthur Melnick for prompting me to clarify this point and suggesting the particular locution I have adopted. A similar position, though with differences concerning the Kantian jargon, is developed in depth by Howell (1973). It contrasts with that of Thompson (1972).
} 
hallucinate a unicorn without ever having sensed one, but then the imagination even in this naturalistic manifestation must do something a little more than mimic whole sensory manifolds. I am confident that Kant has as sophisticated resources as any to deal with standard complications like these. Some have already been mooted and some will come out in what follows. What I want to do now, however, is move on to the second core class of non-veridical experience, illusion.

\section{3.}

For present purposes I will treat illusions as cases in which an object is experienced as possessing properties it does not as a matter of fact possess. A canonical example is seeing a straight stick half submerged in water and its looking bent. To understand Kant's account of illusion we need to turn in more detail to the role of the concept of an object.

There is a crucial ambiguity in this notion between a representation that involves no empirical elements and a representation that involves some empirical elements, albeit alongside pure elements. It is specifically the concept of an object in general that involves no empirical elements. This is the concept articulated by the categories. There are both schematized and unschematized versions of it, depending on whether it is separated from our particular modes of sensibility, space and time. The unschematized concept of an object in general is not my concern here. It is something like the concept of a whole with parts that enjoys some more or less limited reality and which can stand in some kind of ground and consequence relation to other such things. Many things qualify as objects in this sense, including noumena and Platonic abstracta. The schematized concept of an object, on the other hand, is more restrictive. It is something like the concept of a spatiotemporally extended and located, sensible propertypossessing, fully causally functioning, really existing particular, event, or state of affairs. So the categories are mobilized wholesale, as collectively articulating this concept of an object in general.

Paradigmatic of such objects are medium sized dry goods, like tables and chairs. Yet what makes it the concept of an object in general is that what further empirical concepts 
are instantiated is left undetermined. If something is cognized as an object in general then it could but is yet to undergo further descriptive specification according to what particular sensible properties it happens to possess, such as that of being rectangular or that of being wooden or that of being a table. Once one starts to specify in this way then one is no longer working solely with the pure, categorial concept of an object in general. It becomes, for example, the concept of an object that is rectangular and wooden. The categories are still involved - since whatever instantiates the species instantiates the genus - but there is now an admixture of the empirical as well. ${ }^{17}$

This point also has its judgemental counterpart. The judgement that there is an object here and now does not involve any concepts other than the categories (assuming that whatever spatiotemporal determination it involves is non-conceptual). But it could be empirically specified without altering its basic structure simply by adding predicates. Our experience might be as of a rectangular wooden object here and now, to which the corresponding judgemental counterpart would be that there is an object that is rectangular and wooden here and now.

The relevance of this distinction for hallucination is that things go wrong at the categorial level, before any empirical specification takes place, for there is nothing perceptually present that is spatially located and extended, fully causally functioning, or really existing.

But what has this got to do with illusion? Like hallucination, illusion is at a normative (=representative) level of cognitive output and involves a mistake of some kind. To continue a passage from which I quoted earlier:

Thus the human being often mistakes what is subjective in his way of representation for objective (the distant tower, on which he sees no corners, seems to be round; the sea, whose distant part strikes his eyes through higher light rays, seems to be higher than the shore (altum mare); the full moon, which

\footnotetext{
${ }^{17}$ Note, however, that even prior to empirical specification the pure concept of an object, in both its schematized and unschematized versions, is descriptive. Indeed I take this to be a definitional characteristic of concepts per se. It therefore stands in place of the predicate rather than the variable in sentences like 'there is an $x$, such that Fx'. If anything plays an analogous role to that of the variable here - and we have to be very careful in translating into an anachronistic idiom - it is intuition. (See the comment below on how to articulate the principled distinction between hallucination and illusion.)
} 
he sees ascending near the horizon through a hazy air, seems to be further away, and also larger, than when it is high in the heavens, although he catches sight of it from the same visual angle). And so one takes appearance for experience; thereby falling into error, but it is an error of the understanding, not of the senses. $(146)^{18}$

But unlike hallucination, this mistake does not occur at the level of categorization. In cases of illusion, the application of the categories, bare as they are, is entirely correct. Unlike hallucination, there is in cases of illusion an occurrent act of outer sensing, so there is indeed in the subject's perceptual presence something that instantiates the concept of an object in general, that of a spatiotemporally extended and located, sensible property-possessing, fully causally functioning, really existing particular, event, or state of affairs. Illusion, then, goes awry at the level of empirical specification, when a subject ascribes properties like roundness, highness, farness and largeness.

Note, however, that it is not empirical specification per se that causes the problem. When I experience a straight stick as bent, I am correct to apply the concept of an object that is a stick. This concept remains generic enough to be instantiated by the object instigating the illusory experience. What I ought not do is apply the still more specific concept of an object that is a straight stick.

And in the other direction, note that I have not expressed the distinction between hallucination and illusion schematically. For it would not be correct to do so in terms of the difference between 'there exists an $x$ ' (for hallucination) and 'there exists an $x$ such that $x$ is $F$ ' (for illusion), since for all this dictates ' $F$ ' could be a pure categorial predicate like 'causally functioning' or 'property possessing' rather than an empirical one like 'high'.

Sticking with the simple formulation in terms of error at the categorial level and error at the empirical level, then, on the face of it this looks to be a plausible and principled way to draw the distinction. This is primarily because it entails that actual mental malfunction only occurs with hallucination, which is important due to the utter ubiquity

\footnotetext{
${ }^{18}$ Kant gives further examples of illusions at p.137, which include the observation that 'white stockings present fuller calves than do black ones'!
} 
of illusion in comparison to hallucination. Despite the fact that the notion of a mistake is a notionally normative one and we are in some basic sense at a normative level of processing here, in both classifications of non-veridical experience it is ultimately the natural realm that determines whether or not a mistake has occurred; the question of whether or not we are undergoing non-veridical experience, be it of the hallucinatory or illusory variety, ultimately depends on how the world is. Indeed this simply indicates the fact that at the current level of cognitive function the norms in play can be fully articulated by a list of truth-conditions. But in hallucination, and crucially only in hallucination, there is a cause that we can locate more specifically in sensibility. In illusion, sensibility is functioning as usual and we are sensing in exactly the same way as we do when we experience veridically - it is the object and outer sense that are involved rather than the imagination and inner sense. Unlike Macbeth seeing a dagger, there is nothing wrong with the subject who sees a stick looking bent when half submerged in water.

Still, we need to elaborate a little, for going on what we have so far one might worry that cases of radical misrepresentation will get incorrectly classified. If a subject is looking at a chair but seeing an elephant, intuitively it would be correct to say that she is hallucinating. This kind of case seems radically different to that in which someone sees a white chair as red due to nonstandard light conditions. But the categories might appear to remain applicable. Should it then be classified as illusion? In fact the current model very naturally suggests how we are to deal with such cases.

The categories are applied uniformly across all manifolds irrespective of contingencies of content, for all empirical intuitions are as of objects in general. Whether I perceive a bird or a tree or a bird in a tree or a bird flying out of a tree, for example, I perceive a spatiotemporally located and extended, sensible property possessing, fully causally functioning, particular, event, or state of affairs. With empirical concepts however, just which ones are mobilized in the production of any given experience is determined by the particularities of the relevant intuitions. Not all intuitions are caused in us by red things, for example, so not every experience will require us to mobilize the empirical concept of red or be as of an object that is red. In this way the activity of the understanding counts as radically spontaneous in its categorization of the sensible 
manifold, and yet at the same time can remain constrained from below insofar as it also consists in the application of empirical concepts. ${ }^{19}$

In the kind of case proffered above, the bottom-up constraint is clearly missing, and this indicates that there has indeed been some mental malfunction, that there has been a break in the mechanistic chain. A good explanation of such a case would require positing the surreptitious working of the imagination, for the fact that there is a chair present is explanatorily irrelevant. The categories do not remain applicable because they have not been applied to a manifold caused by that chair at all. In this way such cases would qualify (correctly) as hallucinations. ${ }^{20}$

\section{4.}

Having addressed the mechanisms involved in both canonical classes of non-veridical experience and utilized distinctive Kantian tools to suggest a principled distinction between them, we need to confront an issue that applies generally in this context. Any vaguely credible account needs to allow room for cases in which the subject is aware that her experience is non-veridical. The motivation is not merely that non-veridical experience is rarely if ever actually subjectively indistinguishable from veridical experience. Even if this were common, the fact would remain that our ulterior knowledge of the way the world works could well inform how we decide to take the evidence of our senses. Yet at first it might seem as though Kant cannot cope with this simple and ubiquitous phenomenon, for he ties experience too closely to judgement. If I know that my experience is in some way non-veridical when, for example, I see a stick half submerged in water looking bent, then surely I ought not to judge that there is a bent stick here and now. Indeed it seems plausible that I ought to judge that it is not the case that there is a bent stick here and now. The worry is that something like a Moorean paradox arises for subjects who do what they ought in such cases; that in cases of self-

\footnotetext{
${ }^{19}$ See Watkins (2008) for an extended treatment of this anti-McDowellian point. Note also that I take this characterization of spontaneity to be entirely compatible with the more standard one (which does not distinguish between the empirical and pure manifestations of the understanding): deploying spatiotemporal concepts - i.e. both empirical ones, which are automatically spatiotemporal, and pure ones, which are spatiotemporal when schematized - does not carve the world of things-in-themselves at its joints.

${ }^{20}$ Further complications include Müller-Lyer cases, in which it is also far from clear that there is 'nothing wrong' with susceptible subjects.
} 
aware non-veridicality rational subjects judge that the stick is bent and that it is not bent. And this worry is not specific to illusion. The same would apply if Macbeth decided that what he saw before him was in truth a dagger of the mind, a false creation, proceeding from the heat-oppressed brain. Fortunately, this objection underestimates the complexity of Kant's model.

I have talked about judgemental counterparts to distinguish the kind of thing that accompanies experience from what we might call full blown judgement. The basic thought is that these are significantly different kinds of representation, occurring at different levels of cognitive engagement, indeed with different attendant kinds of normativity, and that this allows room for a subject to be able, coherently, to make full blown judgements that contradict her experiential judgemental counterparts. This needs some explanation.

By full blown judgement I mean the kind of unification of concepts that Kant so famously divides into analytic and synthetic. Both full blown judgement and the judgemental counterpart to experience qualify as judgement because they constitutively involve concepts and are objectively valid in the sense that they are truth-evaluable. However, full blown judgement constitutively involves only concepts. Experience and its judgemental counterpart, on the other hand, constitutively involve concepts and intuitions - in experience we unify intuitions with concepts, not just concepts with concepts. The involvement of concepts at all is enough to secure a kind of judgemental form, but the constitutive involvement of intuitions ensures that it is of quite a unique kind. The most important and general consequence of this has to do with the relative primitiveness of experience in comparison to full blown judgement. There is a definite hierarchy here. Experience and its judgemental counterpart justify or provide rational ground for full blown judgement. They are not equivalent to it. For example, the full blown synthetic a posteriori judgement that some sticks are bent would normally garner justification from the experience as of a bent stick and the judgemental counterpart that there is a bent stick here and now. But this relation only holds firm in epistemically suitable situations. It can readily be overridden by a variety of countervailing factors, as when a subject is fully aware that putting straight sticks in water does not bend them. 
Another way to approach this issue, and one that will bring us back to the text of the Anthropology, is via the notion of consciousness. Kant defends the explicitly antiLockean doctrine that we can 'have representations and still not be conscious of them'. In particular:

The field of sensuous intuitions and sensations of which we are not conscious, even though we can undoubtedly conclude that we have them; that is, obscure representations in the human being (and thus also in animals), is immense. Clear representations, on the other hand, contain only infinitely few points of this field which lie open to consciousness; so that as it were only a few places on the vast map of our mind are illuminated. (135)

It seems as though Kant virtually defines intuitions and sensations as obscure in this passage, and experience as clear, for remember that whole manifolds of informationencoding natural mental states must be conceptually unified by the understanding in order to produce a single representational experience as output. If so, we are not given manifolds in any sense that allows us to consciously choose how to conceptualize them - we do not consciously decide how to process our data set, and although the activity of the understanding is more intellectually sophisticated than the activity of the imagination, it is not as sophisticated as voluntary action. ${ }^{21}$

One could go further and say that we are not normally conscious at the level of sensibility at all and that the understanding is itself partly constitutive of normal human consciousness. But this is a difficult and controversial issue. ${ }^{22}$ Fortunately, all that is essential here is the much weaker claim that it is only on the basis of consciousness as of objects that we do things like make decisions. This is enough to produce the required hierarchy between full blown judgement on the one hand and experience and its judgemental counterpart on the other. For one especially salient way to make a decision is to make a full blown judgement about how the world is. Now that is not to say that experience is entirely neutral in this regard. After all, it presents us with the world as

\footnotetext{
${ }^{21}$ Bennett $(1974,19)$ makes this mistake, presumably unaware of Kant's discussion in the Anthropology of 'the involuntary course of one's thoughts and feelings' (133).

${ }^{22}$ Kant certainly acknowledges some form of consciousness at the level of bare sensation (see e.g. B207, A320/B376), but it is not at all clear what role it plays or how we should characterize it. Sellars (1975) and George (1981) offer deflationary adverbial accounts.
} 
being thus and so, not merely as possibly being thus and so. In modern parlance we might say that experience does not simply provide us with bare propositional content but also prompts us to adopt an attitude of belief towards it; or that experience both supplies accuracy conditions and suggests that they are fulfilled. But what is crucial is that experience has this manner even if we know that the world is not thus and so. As Kant says, 'Illusion is that delusion which persists even though one knows that the supposed object is not real' (149). ${ }^{23}$ And it is precisely because we have no choice in the matter that we fall short at this level of making the kind of commitment typical of full blown judgement. Under epistemically optimum conditions we can readily consent to asserting that the way the world is presented as being in experience is indeed the way the world is. Yet we could also resist this if there were reason to do so. The conscious strengthening of propositional attitude, in either direction, represents a decision and constitutes a cognitive shift up from the level of experience and its judgemental counterpart to the level of full blown judgement.

Note that the claim is not that every judgement actually involves something that could be correctly described as a choice. This would be implausible, for judgements can surely be as unbidden and uncontrolled as experience. Rather the claim is that every judgement possibly involves this kind of thing. But this is enough to bring with it a much richer and more thoroughly Kantian kind of normativity. The mere possibility of exercising a certain freedom makes judgement normatively binding in a way that experience is not. Ultimately, in fact, it means nothing less than that judgement is governed by a categorical imperative. But all that is crucial here is that, according to Kant's model of the human mind, the case of self-aware non-veridicality is not analogous to a Moorean paradox at all. It is far more like the case of deciding to do one thing whilst nevertheless being tempted to do another, and in this there is no hint of irrationality, merely humanity.

\section{5.}

If the account I have given in the preceding four sections were complete, there would be immediate repercussions for several central disputes in contemporary Kant scholarship.

\footnotetext{
${ }^{23}$ Cf. A293/B349-A298/B355, where Kant discusses the fact that non-veridical experience shares this feature with the transcendental illusion against which his Critical method is designed guard.
} 
In particular I am thinking of two issues that draw heavily on recent work in analytic philosophy of perception.

First of all, the account I have sketched is clearly not naive realist. ${ }^{24}$ I mean by naive realism the particular form of disjunctivism about hallucinatory experience that maintains it is of a fundamentally different kind to veridical experience because veridical experiences have as metaphysical constituents their real world objects. Neither intuition nor experience, as I have understood these notions, are relational in the sense that they require the actual and current existence of their objects. For we have seen that one species of experience is hallucination, and that the representations produced by the imagination's affect upon inner sense therein are a species of intuition. Though we have also seen that hallucination is essentially reproductive, that it is ultimately parasitic upon genuine causal interaction with the external environment, so there does seem to be at work some weaker, externalist sense in which intuition and experience depend on that environment. And there might even be room for weaker forms of disjunctivism, though this is not least because of the broadness of disjunctivism's criterion of fundamental difference. ${ }^{25}$ Despite the similarity of structure and constituent on the current picture, it is not obvious that it should not count as a fundamental difference between veridical and hallucinatory experiences that only in the former are we in direct causal contact with actual objects, especially if we consider that this issue might well partially determine whether or not the episode in question can be theoretically and practically assimilated into a single, law governed picture of the world.

Second, as I have explained it here Kant's model is not one that actively makes room for non-conceptual world-oriented content. Very roughly, the content of a mental state is what is conveyed to the subject who is in that state; this content is world-oriented if it is intentional in some suitable sense and puts the subject in cognitive touch with the world in some suitable way; and it is non-conceptual if it is not itself conceptually structured, for example in a way analogous to the semantic structure of a proposition, and does not itself constitutively involve concepts. ${ }^{26}$ Going solely on what I have said

\footnotetext{
${ }^{24}$ Contra e.g. Hanna (2010) and Allais (2010).

${ }^{25}$ See Soteriou (2010).

${ }^{26}$ In fact there is a much weaker sense in which one might think content could qualify as non-conceptual, namely if it does not require the subject to possess concepts which would enable her to interact with it in certain ways, such as describe it. I cannot discuss this influential alternative in these brief remarks, except
} 
above, Kant thinks that mental content is either non-conceptual but not world-oriented sensation/intuition/information-encoding natural representation - or world-oriented and conceptual - experience. For all we have seen here, there is no middle ground. ${ }^{27}$

However, the account I have given is clearly not complete - there is clearly much more to say. And so in light of this I in fact make no claim to have established either that Kant was not non-conceptualist about some world-oriented content or that none of the Kantian classes of representation are object-dependent in the naive realist, relationalist sense. To positively rule these out would require much fuller treatments of all the key notions of 'imagination', 'intuition', 'concept' and 'experience', not to mention 'synthesis' (which I have talked about in terms of processing and function). But I do think anyone would be forced to admit that Kant uses each and every one of these absolutely pivotal terms in different ways at different points, and the research questions would include: Is there a significant usage of 'intuition' where it denotes something in between a spatiotemporally ordered manifold of sensations and full cognitive experience? Or is there a significant usage of 'experience' according to which it remains objective but does not require the understanding? Ought we to impose an principled distinction between intuitions and imaginings, even though Kant simply does not make one terminologically explicit and regular? And is there a much richer role for the imagination that yet does not go as far as rendering it subordinate to the understanding? I do not claim to have answered or even addressed any of these questions.

Nevertheless, there are several points at which my account, such as it is, goes against the explanatory grain of the positions under consideration. For example, I have shown that Kant's model has the resources to provide quite a rich bottom-up explanation of both canonical classes of non-veridical experience as well as the general potential for subjective indistinguishability. Modern day naive realists, on the contrary, tend to use subjective indistinguishability as a primitive, and they do so in order to offer a much more austere definition of non-veridical experience, as merely that which is subjectively indistinguishable from veridical experience. And concerning the issue of nonconceptualism, one of its key motivations is the idea, which is very natural indeed, that

simply to say that it does not look especially Kantian (see Hanna (2010) for quasi-independent reasons to suspect its robustness as a form of non-conceptualism).

${ }^{27}$ Contra e.g. Hanna (2008), Hanna (2005) and Allais (2009), and in line with Ginsborg (2008). 
experience is more basic than judgement, that seeing is not believing. Yet by considering how Kant could deal with self-aware non-veridicality we have seen that he makes room for this distinction within varieties of conceptually structured representation.

Moreover, the way I have explained the Kantian concept of an object in general as collectively articulated by the categories can be put to work in a similar regard. A key argument in favour of the relational view of experience is that it is necessary to explain how we can derive concepts from experience, and in particular the concept of mindindependence. Now it is a complex matter as to just what this concept amounts to in the context of transcendental idealism, but suppose that mind-independence is entailed by having a spatiotemporal extension and location, being fully causally functioning, and being really existing, which seems highly plausible. Then we have seen that for Kant this is a concept that is precisely not derived from experience. Rather it is mobilized as a necessary and constitutive condition of it. Kant's innatism in this regard discharges much, though admittedly not all, of that essentially empiricist motivation for the relationalist view. ${ }^{28}$ And this tool might also be used to undercut a significant class of arguments in favour of non-conceptualism. For the view I have attributed to Kant is only moderately conceptualist in the sense that, strictly speaking, only the pure categories and not empirical concepts are necessary for experience. Savages can cognitively experience houses as objects in general without having any conception of what a dwelling established for men would be, and although they could not thereby describe the objects of their experiences as such, they could certainly track those objects through spacetime and even causally reason about them in some limited way. ${ }^{29}$

Still, these are really nothing more than promissory notes. I leave a fuller discussion for another occasion.

\section{Conclusion}

In the preface to his Anthropology From a Pragmatic Point of View, Kant defines the discipline as 'the investigation of what he [the human being] as a free-acting being

\footnotetext{
${ }^{28}$ See Gomes (2010) for a much more in-depth treatment of this topic. His target is Campbell (2002).

${ }^{29}$ Cf. the Jäsche Logic (9:33) (and the Dohna-Wundlacken Logic (24:702)).
} 
makes of himself, or can and should make of himself' (119). So formulated, it sounds very broad. The references to autonomy and normative injunction imply that it is to include moral philosophy, and this relationship has been much discussed. Less attention has been paid to the fact that such marks are equally apt to pick out key aspects of Kant's theoretical philosophy. The spontaneity exhibited by the human mind in its application of concepts (in particular the pure ones), the freedom the conscious agent can express in deciding what make of her experiences, and the rich and complex normative structure of the realm we thereby enter, are all foundational issues in Kant's mature philosophy of mind and epistemology. And though we have seen that the spectre of non-veridicality is built right in to the nature of the human mind on Kant's model, ${ }^{30}$ it remains the case that we ought not be seduced into making false judgements on the basis of it. We should make of ourselves beings who agree with one another, and are right, about the world. ${ }^{31}$

\section{Bibliography}

Allais, L. (2009): Kant, Non-Conceptual Content and the Representation of Space, in: Journal of the History of Philosophy 47, pp. 383-413.

Allais, L. (2010): Kant's Argument for Transcendental Idealism in the Transcendental Aesthetic, in: Proceedings of the Aristotelian Society 110, pp. 47-75.

Arens, P. E. (2010): Kant and the Understanding's Role in Imaginative Synthesis, in: Kant Yearbook 2, pp. 33-52.

Beck, L. W. (1978): Did the Sage of Konigsberg Have No Dreams?, in: L. W. Beck (ed.): Essays on Kant and Hume, London, pp. 38-60.

Bennett, J. (1974): Kant's Dialectic, Cambridge.

Brandt, R. (1999): Kritischer Kommentar zu Kants Anthropologie in pragmatischer Hinsicht, Hamburg.

Campbell, J. (2002): Berkeley's Puzzle, in: J. Hawthorne and T. S. Gendler (eds.): Conceivability and Possibility, Oxford, pp. 127-143.

Crane, T. (2006): Is There a Perceptual Relation?, in: T. S. Gendler and J. Hawthorne (eds.): Perceptual Experience, Oxford, pp. 126-146.

\footnotetext{
${ }^{30}$ In fact this suggests another structural connection to anthropology (even more broadly construed), for it is Kant's anthropic turn that leads him to his data-processor model in the first place. Contrapositively put, God could not undergo non-veridical experience. There is an intriguing passage in the Critique of Judgment (5:401-3) that can be read as elaborating on this connection.

${ }^{31}$ In addition to those already mentioned, I would like to thank Keith Wilson and the other attendees of the Warwick work in progress seminar, an anonymous reviewer from the Kant Yearbook, Bob Hanna, Anil Gomes, and above all Ralph Walker for such useful comments on earlier drafts of this article.
} 
Frierson, P. (2009): Kant on Mental Disorder. Part 1: An Overview; Part 2: Philosophical Implications of Kant's Account, in: History of Psychiatry 20, pp. 267-310.

George, R. (1981): Kant's Sensationism, in: Synthese 47, pp. 229-255.

Ginsborg, H. (2008): Was Kant a nonconceptualist?, in: Philosophical Studies 137, pp. $65-77$.

Gomes, A. (2010): Kant and the Explanatory Role of Experience, unpublished MS.

Hanna, R. (2001): Kant and the Foundations of Analytic Philosophy, Oxford.

Hanna, R. (2005): Kant and Non-Conceptual Content, in: European Journal of Philosophy 13, pp. 247-290.

Hanna, R. (2008): Kantian Non-Conceptualism, in: Philosophical Studies 137, pp. 4164.

Hanna, R. (2010): The Rational Human Condition, unpublished MS.

Howell, R. (1973): Intuition, Synthesis, and Individuation in the Critique of Pure Reason, in: Nous 7, pp. 207-232.

Hume, D. (1978): A Treatise of Human Nature. Eds. L. A. Selby-Bigge and P. H. Nidditch, Oxford.

Kant, I. (1998): Critique of Pure Reason, ed. and trans. P. Guyer and A. W. Wood, Cambridge.

Kant, I. (2000): Critique of the Power of Judgment, ed. P. Guyer, trans. P. Guyer and E. Matthews, Cambridge.

Kant, I. (2001): Lectures on Metaphysics, ed. and trans. K. Ameriks and S. Naragon, Cambridge.

Kant, I. (2002): Theoretical Philosophy after 1781, eds. H. Allison and P. Heath, trans. G. Hatfield, M. Friedman, H. Allison and P. Heath, Cambridge.

Kant, I. (2004): Lectures on Logic, ed. and trans. J. M. Young, Cambridge.

Kant, I. (2007): Anthropology, History, and Education, ed. G. Zöller and R. B. Louden, trans. A. Gregor, P. Guyer, R. B. Louden, H. Wilson, A. W. Wood, G. Zöller, A. Zweig, Cambridge.

Longuenesse, B. (1998): Kant and the Capacity to Judge, Princeton.

McDowell, J. (1998): Having the World in View: Sellars, Kant, and Intentionality, in: Journal of Philosophy 95, pp. 431-491.

McDowell, J. (1996): Mind and World, Cambridge.

Sellars, W. (1968): Science and Metaphysics: Variations on Kantian Themes, London.

Sellars, W. (1975): The Adverbial Theory of the Objects of Perception, in: Metaphilosophy, pp. 144-160.

Soteriou, M. (2010): The Disjunctive Theory of Perception, in: The Stanford Encyclopedia of Philosophy (Winter 2010 Edition), ed. Edward N. Zalta, URL = <http://plato.stanford.edu/archives/win2010/entries/perception-disjunctive/>.

Strawson, P. F. (1971): Imagination and Perception, in Foster and Swanson (eds.): Experience and Theory, London, pp. 31-54.

Thompson, M. (1972): Singular Terms and Intuitions in Kant's Epistemology, in: Review of Metaphysics 26, pp. 314-343.

Watkins, E. (2008): Kant and the Myth of the Given, in: Inquiry 51, pp. 512-531.

Westphal, K. (2004): Kant's Transcendental Proof of Realism, Cambridge. 